Article

\title{
Learning Plant Biodiversity in Nature: The Use of the Citizen-Science Platform iNaturalist as a Collaborative Tool in Secondary Education
}

\author{
Andres Echeverria ${ }^{1} \mathbb{D}$, Idoia Ariz ${ }^{1,2} \mathbb{D}$, Judit Moreno ${ }^{1}$, Javier Peralta ${ }^{3, * \mathbb{D}}$ and Esther M. Gonzalez ${ }^{1, * \mathbb{D}}$ \\ 1 Institute for Multidisciplinary Applied Biology (IMAB), Public University of Navarra, \\ E-31006 Pamplona, Spain; andres.echeverria@unavarra.es (A.E.); idoia.ariz@unavarra.es (I.A.); \\ jmorenoecheverria@gmail.com (J.M.) \\ 2 Departamento de Biología Ambiental, Facultad de Ciencias, Universidad de Navarra, \\ E-31008 Pamplona, Spain \\ 3 Department of Sciences, Public University of Navarra, E-31006 Pamplona, Spain \\ * Correspondence: javier.peralta@unavarra.es (J.P.); esther.gonzalez@unavarra.es (E.M.G.)
}

Citation: Echeverria, A.; Ariz, I.;

Moreno, J.; Peralta, J.; Gonzalez, E.M.

Learning Plant Biodiversity in Nature The Use of the Citizen-Science Platform iNaturalist as a Collaborative Tool in Secondary Education. Sustainability 2021, 13, 735 https://doi.org/10.3390/su13020735

Received: 26 December 2020 Accepted: 10 January 2021 Published: 14 January 2021

Publisher's Note: MDPI stays neutral with regard to jurisdictional clai$\mathrm{ms}$ in published maps and institutional affiliations.

Copyright: (C) 2021 by the authors. Licensee MDPI, Basel, Switzerland. This article is an open access article distributed under the terms and conditions of the Creative Commons Attribution (CC BY) license (https:// creativecommons.org/licenses/by/ $4.0 /)$.

\begin{abstract}
Biodiversity is a concept of great scientific interest and social value studied in different subjects of the secondary education curriculum. Citizen-science programs may contribute to increasing the engagement of students when studying biodiversity. This work aimed to explore the use of the citizen-science platform iNaturalist as a complement of the elaboration of herbaria in an outdoor activity for 4th course 16-year-old students in the Basaula Reserve. The platform iNaturalist was chosen for its suitability to develop collaborative projects in an educational context. The Basaula project was created and 122 students were trained to record plant species in an outdoor activity. A total of 32 species were recorded, among them the most abundant were beech (Fagus sylvatica) and holm oak (Quercus ilex). The students positively evaluated their experience, highlighting its adequacy to record biodiversity data and make a virtual herbarium. Students valued the innovative character of iNaturalist and its usefulness for research but also the opportunity to integrate mobile devices in school education. We concluded that iNaturalist is a valuable tool to carry out collaborative projects dealing with biodiversity in secondary education.
\end{abstract}

Keywords: iNaturalist; citizen-science; secondary education; biodiversity informatics; species identification; smartphone applications; outdoor education

\section{Introduction}

The term "biodiversity" is often used to refer to species richness; however, it has many different facets [1]. Biodiversity comprises the entire variety of life on Earth including all of its levels of complexity (from genes to ecosystems) and considers the evolutionary, ecological, and cultural aspects and processes that make life possible [2]. According to Mishler [3], "Biodiversity is the whole tree of life". Thus, biodiversity conservation is a key step toward preserving our "tree of life" as well as the productive assets and services that provide our existence and well-being [4].

In Spain, the concept of biodiversity is part of the basic curriculum in compulsory secondary education (CSE), especially in the subjects of biology and geology. Through three courses out of the CSE curriculum's four courses, the different kingdoms and classification systems of living beings and the concept of species (1st course), ecosystems (2nd), and their structure, dynamics, and self-regulation (4th) are studied [5]. In addition to the necessary knowledge and skills that allow students to acquire a scientific culture, secondary education must involve students as active agents in society, promoting respect towards oneself, others, and the environment. Furthermore, it should engage them to contribute to the development of their environment throughout their actions and knowledge. This engagement in connection with biodiversity can be achieved through the involvement in citizen-science 
programs that enable experts and professionals to connect amateur naturalist citizens and students, easing the process to recruit, engage, and retain the general public in scientific experiences at different stages of the scientific process [6,7].

In the framework of teaching CSE biology, outdoor activities are commonly used to learn, in situ, the different concepts of the natural sciences. For example, in Nuestra Señora del Puy School (Navarre, Spain), over the last 25 years, students have visited the Nature Reserve of Basaula (see location at the Figure 2) with the purpose of exploring the herbaria of trees and shrubs as a method to learn plant morphology and species taxonomy. These traditional teaching activities are optimum scenarios, as they integrate the use of new technologies and collaborative platforms to create a virtual herbarium $[8,9]$. It is a means of introducing students to the activities of citizen-science and to show them how to broaden the scope of local primary data on biodiversity when putting together global data sets. The first step in doing so is to choose a citizen-science platform appropriate to be used in secondary education to build collaborative virtual herbaria.

Although there are some long-standing citizen-science projects, such as the Christmas bird count in the USA, running since 1900 and probably the longest citizen-science project in the world [10], it was not been until the end of the 1990s and the 2000s that these activities blossomed. This upheaval has been grounded in the widespread use of the Internet and mobile devices, supported by technologies that allow user-generated content and social networking in the context of the "Web 2.0" movement [6,11].

Over the last few years, a multitude of citizen-science tools have been developed [12] that allow, among other things, to address the issue of biodiversity of species and monitoring them around the world in quasi real-time. Some of these biodiversity tools (e.g., iNaturalist, Natusfera, Observation.org, and P1@ntNet) allow for uploading of non-identified observations, so that the users, with different degrees of expertise in species classification may propose an identification, which other users, or sometimes an expert team, subsequently confirm or correct. The identification can be based on precedent observations already in the platform with automatic recognition algorithms.

Table 1 shows the main citizen-science platforms recording species at the global scale and displaying them on interactive maps or database servers. In addition, most of these platforms have desktop and mobile device interfaces. Among the fields to be completed for any observation, date and location are mandatory as happens with herbarium specimens. Most of the platforms also require photographs so other users or experts can validate the observations.

Table 1. Citizen-science programs that record species distributions at the global scale with data sets available in the Global Biodiversity Information Facility (GBIF). C: Community validation, E: expert validation.

\begin{tabular}{ccc}
\hline Platform Name & Species Group & Validation Type \\
\hline eBird & Birds & E \\
iNaturalist & All & C \\
Map of Life & All & C \\
Natusfera & All & C \\
Observation.org & All & E \\
Pl@ntNet & Flora & C, E \\
\hline
\end{tabular}

Among all of the available platforms, the far-reaching mobile application iNaturalist may be considered one of the most appropriate platforms to work with secondary students on the concept of biodiversity. This is due to the fact of its large amount of crowdsourced data, its interactivity and interconnectivity between users, ease of use (i.e., perceptive interface), integration of information into a single device, and compatibility with different mobile software [13].

Most of these participative platforms share their records in the international network Global Biodiversity Information Facility (GBIF) that offers open and free access to biodi- 
versity data about all types of life on Earth [14]. Governments and organizations from a number of participating countries around the world fund this international research infrastructure. This network is aimed at providing anyone, anywhere, access to data about all types of life on Earth [14]. The current power and potential of collaborative citizen-science platforms in biodiversity monitoring in a climate changing scenario through massive data collection, gain special importance in specific taxonomical groups less "attractive" for people such as fungi [15] or plants [9].

In the 21st century, education tools in biology and natural history are experiencing a sudden adaptation from traditional learning activities to the complementary emerging informatics technologies $[9,16]$. In higher education, there are long-term studies ( $>5$ years) with positive results on the implementation/integration of these crowdsourced platforms in university coursework in natural history $[8,9]$. The introduction of these collaborative tools in secondary school curriculum would help ease the students into the topic of biodiversity, making them feel motivated and confident participants in their own learning process, and this would also aid in the better understanding of some of the abstract and theoretical concepts included in the secondary curriculum such as biodiversity [17]. Some citizenscience projects related with plants have been successfully developed, drawing students' attention [18-21]. The use of citizen-science platforms, such as iNaturalist, in secondary schools might engage Spanish students, increasing their curiosity of nature and science, as has been already done in different universities $[8,9]$. There is evidence that working on ecological experiments together with scientists can increase students' knowledge and curiosity about science in general [19-21].

The objective of this study was to implement a collaborative project and attain experience for 16-year-old students in biology courses using the citizen-science platform iNaturalist. Moreover, we evaluated students engagement reached. For such a purpose, a two-year study was performed, creating a collaborative iNaturalist project to record plant diversity in a close natural area surrounding the high school center. In parallel, the students created a traditional herbarium. After both field activities, the students fulfilled a simple questionnaire as a first evaluation of their perceptions and acceptance of the emerging citizen-science teaching tools to learn plant biodiversity.

\section{Materials and Methods}

Two groups of 16-year-old students enrolled in the 4th course on biology (CSE) from the Nuestra Señora del Puy School in Estella (Navarre, Spain) were trained to take part in the project, one group in 2016 (57 students) and the other in 2018 (65 students). The experiment consisted of three sessions as part of their biology lessons: (1) project presentation and protocol (50 $\mathrm{min})$; (2) field activity to make a traditional herbarium and register plant observations for the common virtual herbarium (5 h); (3) upload of observations, explanation, and evaluation of the activity (50 $\mathrm{min})$.

\section{1. iNaturalist Project Design and Presentation}

First, a virtual project called "Basaula Project" was generated by the teacher in iNaturalist platform (http:/ / www.inaturalist.org/projects/proyecto-basaula) in honor of the Natural Reserve where the field survey would be carried out. In 2018, some of the species present in the reserve were registered in a "Plant Guide" in the iNaturalist tool as a support information space for students (www.inaturalist.org/guides/7275). Secondly, one week before the fieldwork class, a 50-min lesson was dedicated to explaining to the students how to operate the iNaturalist application. During this session, each student set-up their own iNaturalist account and joined the Basaula Project (Figure 1). 


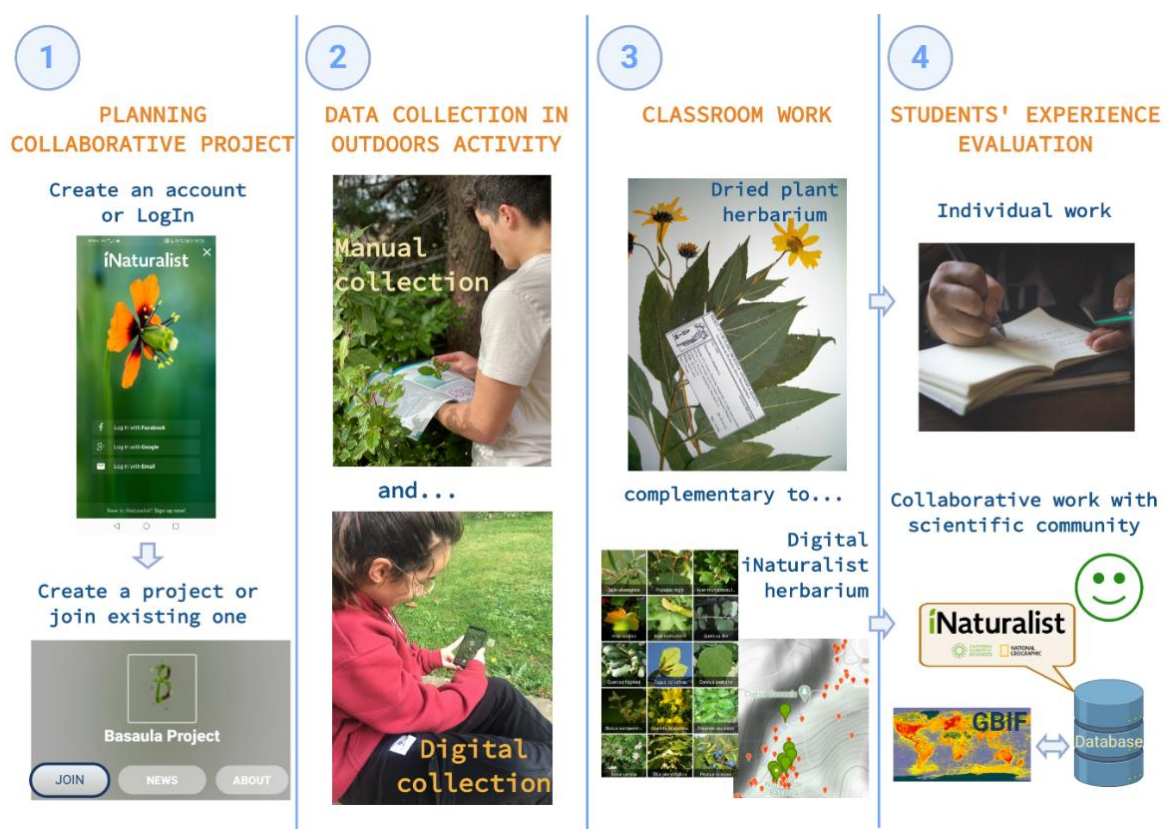

Figure 1. Global view of the Basaula Project experience: From planning (step 1) and procedures for data collection (step 2) and the subsequent classroom work (step 3), to teaching/learning tools for the evaluation step (step 4). Figure created with BioRender.com.

\subsection{Field Activity and Data Collection}

The second session consisted of an outdoor activity, held in May for both years. The students made a 4-km itinerary, accompanied by two teachers and one forest ranger in the Natural Reserve of Basaula; an extra teacher in charge of the iNaturalist project also joined the group. Basaula is located in the Sierra de Lokiz (Navarre, NE Spain), in the fringe of the Mediterranean and Euro-Siberian biogeographical regions with varied woodlands of holm oak (Quercus ilex), pubescent and Valencian oak (Q. pubescens, Q. faginea), beech (Fagus sylvatica), and riverine vegetation (Figure 2).

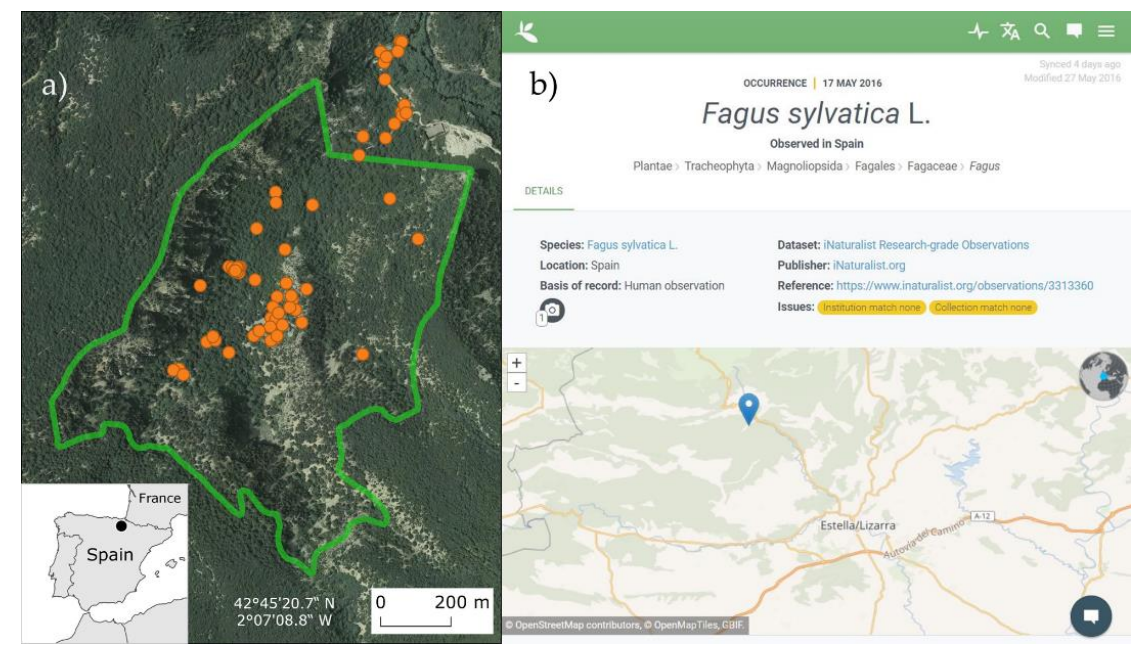

Figure 2. Nature Reserve of Basaula limits and species observations from the Basaula project in iNaturalist [22] with overview map in bottom left corner; WGS84 Geographic coordinates (a); species occurrence from the Basaula project in the iNaturalist data set in the GBIF (b). Map created with QGIS with data from Instituto Geográfico Nacional and iNaturalist (a) and screenshot from GBIF with OpenStreetMap (b). 
The objective was to collect small samples of different trees and shrubs to make a herbarium of dried specimens (Figure 1). In addition, each student was invited to record two observations, also of trees or shrubs, in the iNaturalist project as part of a common virtual herbarium. It was mandatory to record, in situ, the photograph and, if possible, the scientific name of the species; nevertheless, the observation could be completed and uploaded later in class. In addition to the pre-established observation fields of iNaturalist, another three were included: name of the observer, habitat (road border, forest, meadow, etc.), and the common name of the species.

\subsection{Observation Uploading and Students' Experience Evaluation}

The objectives of the third session were to upload the observations, complete the required fields, and explain the results while understanding the validation process and browsing additional information provided by the iNaturalist platform. An important aspect was acknowledging the possibility that the gathered data could potentially be accessible through the GBIF depending on the quality of the observation and of the type of copyright chosen by the user when shared in iNaturalist.

Once the activity was completed, the students were asked to evaluate it. For this purpose, a simple questionnaire (Tables 2 and 3) was designed to obtain feedback from the students about the usability and utility of the iNaturalist tool and the Basaula outside activity itself as an approach biodiversity learning. The meaning of the statements in the questionnaires was clearly explained to the students before they answered.

Table 2. Questionnaire to evaluate the main features of iNaturalist. Positive aspects are marked in beige and shortcomings in lilac.

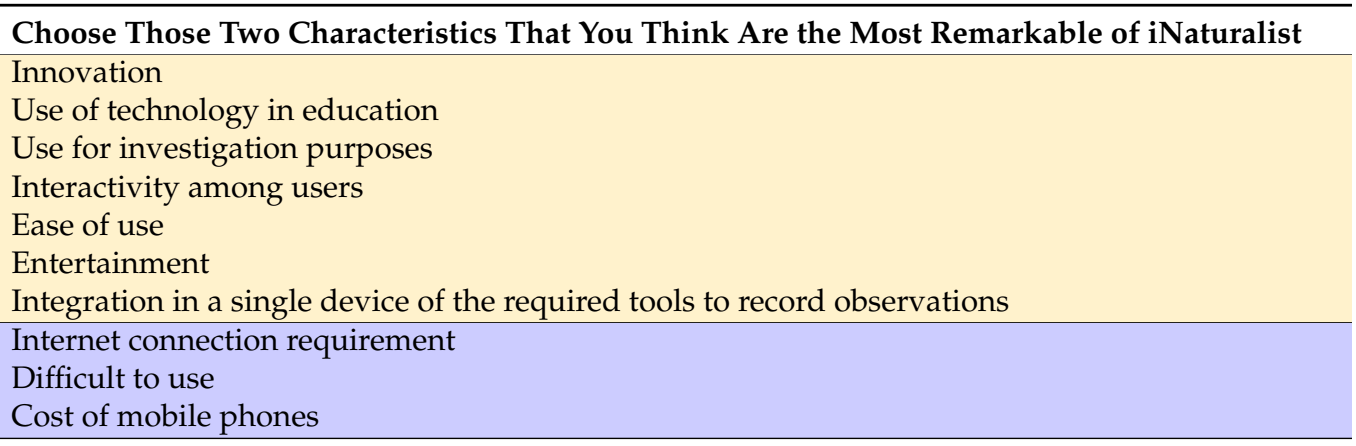

Table 3. Questionnaire to evaluate the suitability of iNaturalist as a biodiversity learning tool and the engagement of the students.

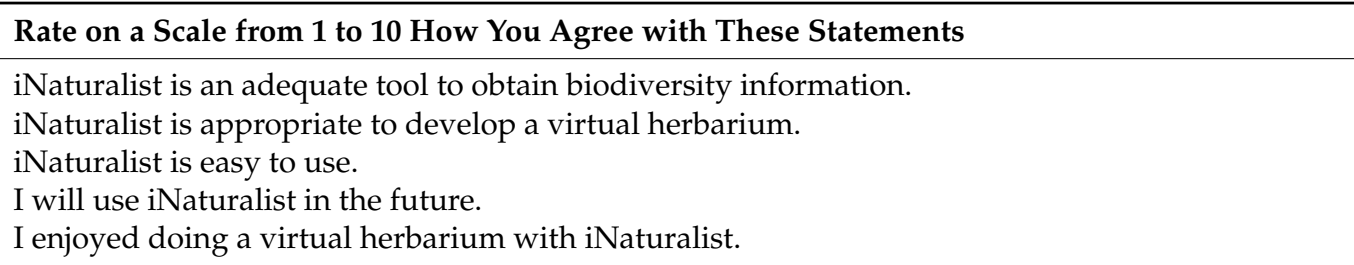

The questionnaire presented in Table 2 was used to obtain information about the usability of the iNaturalist tool by the students. Each student was asked to choose the 2 most highly relevant characteristics associated with the tool's usability (or tool handling), which could be positive or negative (shortcomings), from a list of 10 different attributes. Between the positive ones, ease of use; innovation from traditional handmade herbariums; use of technology, such as mobile phones, in biology learning; interactivity between iNaturalist users; suitability of the application for investigation purposes; integration of the traditional camera-notebook-map in a single platform were selected. The three 
shortcomings were internet connection limitations in some study areas, mobile phone costs, and the difficulty in using the platform.

The students also had to evaluate how they agreed with 5 statements, on a scale from 1 to 10 , about the adequacy of iNaturalist to obtain information on biodiversity and to make a virtual herbarium, its ease of use, and their enjoyment in the activity and willingness to use this application in the future (Table 3). The first two questions attempt to assess the suitability of iNaturalist for use in secondary education to study plant diversity, while the last three could be an indicator of student engagement with the platform [23]. In the 2018 student experience, a new question was included in this questionnaire to understand why students decided not to participate in the iNaturalist Project, which included four possible answers: (1) it is a complex method; (2) I prefer to use the traditional method; (3) I have recorded observations, but I could not upload them; (4) other reasons (open answer).

\subsection{Statistical Analysis}

Data were examined within the SPSS 25.0 package (SPSS Inc., Chicago, IL, USA). Student's $t$-test was employed to compare the main features of the iNaturalist evaluation for the years 2016 and 2018. Data were shown as means \pm standard errors and the number of repeats used in each analysis was specified in the legend of the corresponding figure and table. The 4th course groups involved in the experiment consisted of 56 students in 2016 and 65 students in 2018.

\section{Results}

\subsection{Participation in the iNaturalist Project}

The average participation in the virtual herbarium project of Basaula was $45.9 \%$ (56 students out of the 122 students that completed the group of 4th grade secondary school (Figure 3b)). On the one hand, 29 out of 57 students (50.9\%) participated in 2016, while on the other, 27 out of 65 students (41.5\%) did so in 2018 (Figure 3b).

(a)

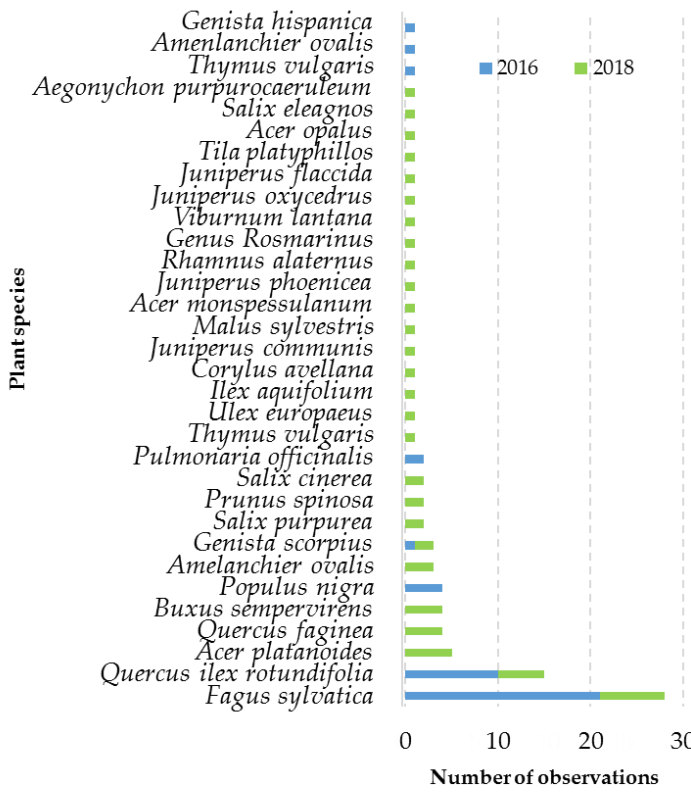

(b)

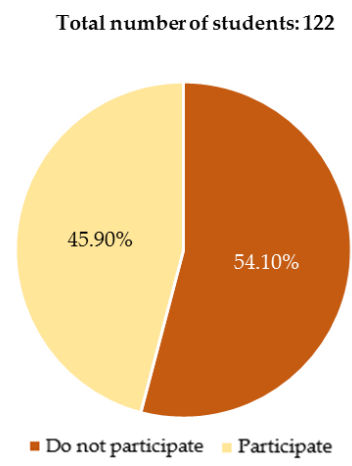

Figure 3. Data from the Basaula Project: the number of observations per species (2016 in blue and 2018 in green) (a); overall participation of the students in percentage (b).

Participant students were considered those that completed all the stages of the virtual herbarium from observation record to its upload in the platform. In 2018, the students that did not participate justified their decision for different reasons: problems uploading the observations (34\%), preferred using traditional method (32\%), and other reasons (34\%) related to the use of mobile phones at the same time they had to take samples for the 
traditional herbarium. In both years, some students stated that they had trouble uploading observations due to the limited or lack of mobile data.

In total, 94 observations were made, representing an average of 1.68 observations per student with 41 observations in 2016 and 53 in 2018. The number of recorded species was 32-8 species in 2016 and 27 in 2018. The two most common recorded species were beech (Fagus sylvatica) and holm oak (Quercus ilex) with 28 and 15 observations, respectively (Figure 3a).

\subsection{Explanation of the Activity and Evaluation by the Students}

In the session after the field activity, the observations not previously uploaded were added to the iNaturalist platform and the results were explained, showing the recorded species and how the validation process was performed. In iNaturalist, observations must be verifiable to be validated; verifiable observations of plant species are those that have geographic coordinates, date, and photographs. They are validated when more than $2 / 3$ of identifiers agree in the assigned taxon; validated observations of not cultivated plants become "research grade". It was shown to the students that the data set of iNaturalist was in the GBIF, and then it was explained how the validated observations with "research grade" status could be part of that data set; moreover, in 2018, it was possible to check how some observations made during the activity in 2016 were already in the GBIF (Figure 2b).

Finally, the students fulfilled two questionnaires to evaluate the usability of iNaturalist and their engagement in the activity (Tables 2 and 3). Figure 4 represents the perceptions about iNaturalist by the students; scores are the percentage of students that selected two positive or negative features out of the ten possible choices. Among the advantages, innovation (scores 22.9 and $22.5 \%$ ), use of technology in education (11.0 and $18.8 \%$ ), suitability for research (13.5 and 18.0), and interactivity (12.5 and 13.9\%) were the characteristics rated with the highest scores. Limitations of internet connection was identified as the main disadvantage but only in 2016 (15.5 and 4.1\%).

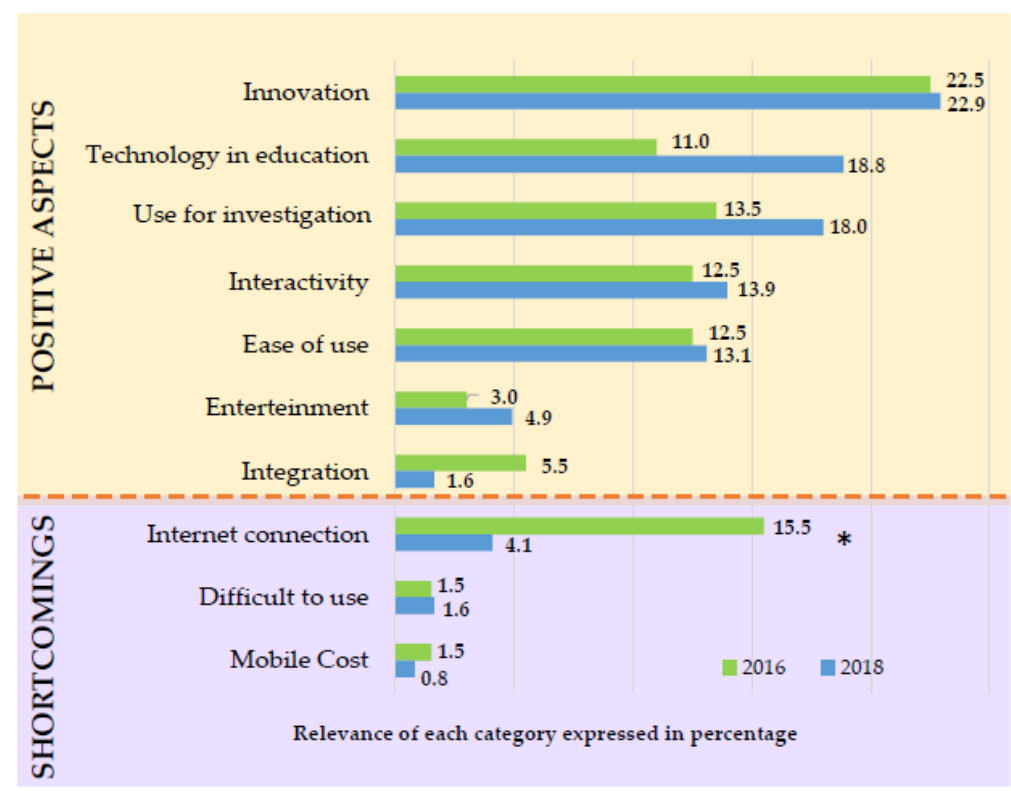

Figure 4. Evaluation of the usability of iNaturalist as a biology-learning tool by the students. The usability features reflect the positive aspects and some shortcomings, which may appear derived from the use of the app in secondary education learning. Each student marked the two most important characteristics in the use of iNaturalist, and the figure shows the relevance of each for the students expressed in percentage. The number of students who answered the 2016 and 2018 questionnaires were 47 and 60, respectively. The asterisk represents significant differences $(p<0.05)$ between 2016 and 2018. 
Regarding the evaluation of the suitability for biodiversity learning using iNaturalist (Table 4), they considered it an adequate application for fieldwork research (8.45 and 8.53 points out of 10) and useful to develop a virtual herbarium ( 8.79 and 8.87 points out of 10). The ease of use (7.57 and 7.87 points out of 10$)$, enjoyment while doing the activity ( 8.15 and 7.22), and their willingness to use the tool in the future (6.96 and 8.17 points out of 10) reflected a positive engagement with the experience.

Table 4. Evaluation of the suitability of iNaturalist for biodiversity learning and engagement of the students. Results indicate mean \pm standard error (SE) of the ratings given by the students that answered the questionnaires in $2016(n=47)$ and $2018(n=60)$ to each statement. No significant differences between years were found.

\begin{tabular}{lccccc}
\hline & \multicolumn{2}{c}{ 2016 } & \multicolumn{2}{c}{ 2018 } & 2016-2018 \\
\hline Question & Mean & SE & Mean & SE & Mean \\
\hline $\begin{array}{l}\text { iNaturalist is an adequate tool to get } \\
\text { biodiversity information }\end{array}$ & 8.45 & 0.20 & 8.53 & 0.16 & 8.50 \\
$\begin{array}{l}\text { iNaturalist is appropriate to develop a } \\
\text { virtual herbarium }\end{array}$ & 8.79 & 0.22 & 8.87 & 0.13 & 8.83 \\
iNaturalist is easy to use & 7.57 & 0.31 & 7.87 & 0.23 & 7.74 \\
$\begin{array}{l}\text { I enjoyed making a virtual herbarium } \\
\text { with iNaturalist }\end{array}$ & 8.15 & 0.26 & 7.22 & 0.29 & 7.65 \\
I will use iNaturalist in the future & 6.96 & 0.36 & 8.17 & 0.24 & 7.64 \\
\hline
\end{tabular}

\section{Discussion}

\section{1. iNaturalist: An Innovative and Complementary Tool to Traditional Herbaria in Secondary Education}

In this work, we implemented a collaborative biodiversity project on the subject of biology for 4th course students in secondary education using the iNaturalist platform and we evaluated their engagement. This outdoor activity to observe and collect plant species, which has been carried out for the last 25 years at the Nuestra Señora del Puy School, gave us the opportunity to integrate the use of new and collaborative technologies to create a virtual herbarium. This virtual herbarium is complementary to the traditional handmade herbarium that the students had to do with 15 specimens of trees and shrubs. Despite the recording of observations of plant species with iNaturalist being voluntary, $45.9 \%$ of the students participated with 1.68 records per student, identifying 32 species, which provides evidence of interest created by this activity (Figure 3). A possible cause could be the positive predisposition of young students to use smartphones $[8,16]$, which was confirmed by the ease of use reported by the questionnaires (Figure 4, Table 4).

This approach has been already done in university courses and in academic herbaria, but to a very limited extent $[9,24]$. The implementation of new technologies in schools is gaining traction, for example, a mobile plant learning system in a Taiwanese elementary school [25] or the development of an illustrated plant identification tool to teach botany in an innovative way [18]. In our study, the students perceived iNaturalist as an adequate tool to obtain biodiversity information, and that it was appropriate for developing a virtual herbarium, rated 8.50 and 8.83 points out of 10 , respectively (Table 4 ). They learned how a mobile phone can integrate traditional tools to record biodiversity data (notebook, camera, GPS), with the basic associated information that makes useful an observation: a photograph with enough quality to be used as a verifiable basis of the record, date, and geographic coordinates of the location. They could see how these data were the same as those associated with a herbarium specimen but with an additional value when shared through iNaturalist.

The integration of this activity is a way to show the power of citizen-science to gather biodiversity observations, and the students could see how it was possible that their observations could be merged with data from academic institutions in the online repository of the GBIF. Those students that participated in the second year's activity had 
the chance to see how some observations made by their older classmates, in 2016, were already published in the GBIF. This could explain the greater scores given for the suitability for research of iNaturalist in 2018 (18 versus 13.5). The students could realize how their observations summed up to widen the spatial and temporal monitoring of biodiversity, its relevance for a global view of patterns and trends, and as a basis for the conservation of nature [12]. It was also an opportunity to explain the importance of Creative Commons Licenses and the consequences that the different eligible types in iNaturalist have for the reuse of data [26].

Citizen-science platforms offer a great potential to add value to traditional field activities in natural history at different education levels and to institutional herbaria $[8,9,24]$. The combined use of traditional and virtual herbaria allowed the students to appreciate the complementarity of both approaches to learn about biodiversity of species. Dried and pressed herbarium specimens can be examined in the laboratory for morphological characters that are not always shown in photographs, such as organ hairs, glands, size, etc., required when dichotomous keys are used for species determination. On the other hand, the virtual herbarium provides images with live colors and allows for comparison with photographs already identified by other users. In this way, students did not rely only on images or suggested species within the application, and it preserved the learning of identification skills based on organ morphology [8]. Another possibility opened using iNaturalist was access to supplementary information such as global distribution maps, phenology patterns, conservation status or position in the taxonomical tree that can be used as additional didactic materials.

Regarding operational problems, the first contact with an unknown application, such as the case of iNaturalist, causes uncertainty in students, so it was necessary to explain on several occasions and thoroughly the steps to follow for its correct use. For this purpose, the support of a simple tutorial with screenshots of the step-by-step workflow of the application was a success the second year of the study. Both years, the students rated iNaturalist as easy to use (7.74 points out of 10), and among its shortcomings, difficult to use as a relevant feature was almost negligible (Figure 4, Table 4). A remarkable drawback for the students was the need for internet connection, especially during the first year. This had to do with the fact that, at the time, it was not sufficiently explained that it was not necessary or even advisable to upload data during fieldwork to extend battery life and because of the eventual lack of network coverage. Nevertheless, mobile phone data availability was a concern even afterwards, as it was pointed out as the reason not to have uploaded observations by a third of the students that did not use iNaturalist. The school's Wi-Fi was not open to students and not everyone had a personal network data, in some cases due to the fact of parental use restriction, as informally reported by some students. These problems highlight the need to integrate the use of mobile devices in schools as well as familiarize parents with the pedagogical benefits of using them in the classroom [27].

On the teachers' side, working with new technologies might pose problems for those unfamiliar with innovative technological methods; in this experience, the use of iNaturalist was only done when external support was provided by additional teachers. This could be due to the already overloaded curriculum with contents that are considered enough and a generational problem that time could overcome [9]. However, this could be an indicator of the need of an external framework to support the inclusion of citizen-science as well as the need to include these tools in the curricula of student teachers [16].

\subsection{Learning Biodiversity Improving Students' Engagement: The Use of Technological Collaborative Tools in Secondary Education}

During CSE for youngsters aged 12 to 16, pupils are provided with knowledge and skills that contribute to their independence and social integration, and their personal development is reinforced. They must achieve a grounded scientific culture, and their active involvement in society to improve the environment throughout their actions and knowledge should be promoted. These students were introduced to the study of ecosystems, trophic networks, and the interaction of organisms with each other and with the environ- 
ment as well as their impact on the dynamics and evolution of these ecosystems. Therefore, the CSE curriculum concerning biology, in addition to theoretical concepts, faces the challenge of engaging students with biodiversity as a first step to committing them as future citizens in the care of their surrounding environment. This particular way of learning science instills community awareness, critical thinking, problem solving, and practical experience in students [6,7].

According to Willms [23], the term "student engagement" is comprised of two components: a psychological one related to the sense of belonging at school and acceptance of school values and a behavioral component associated with participation in school activities. Fieldwork with living organisms is a very efficient method for teaching and learning due to the fact of its experiential character, where students learn by doing and not only listening [28]. Thus, introducing collaborative and innovative activities in secondary education could be a good strategy to increase the behavioral component of the students' engagement within the school $[8,29]$, as suggested by the answers to the survey on involved in the project students' perception. The achievement of this engagement can be deduced from the students' evaluation of iNaturalist: they considered it easy to use, enjoyable, entertaining, and expressed their intention to use the application in the future (Figure 4, Table 4). These perceptions are in accordance with those of university students, who combined outdoor activities to identify species in natural history courses with iNaturalist [8] and a similar application, Nature Atlas [9]; they also found their projects enjoyable, the applications easy to use, and they were likely to use them in the future. The students also valued the innovative character of iNaturalist, the use of technology in education, and the interactivity it provided (Figure 4), suggesting that from the students' point of view the introduction of these technologies is positive. This is the first study applying iNaturalist in secondary education as far as we know. Although further studies need to be developed, our results suggests that the inclusion of citizen-science strategies may improve the biodiversity engagement of secondary school students.

The unstoppable implementation of information and communications technologies [30] is promoting the most important transformation in teaching for 150 years, changing the paradigm from "I teach" to "we learn" [31]. Thus, a pedagogical movement called mobile-learning has arisen, characterized by the construction of knowledge through exploration and conversation in a great variety of environments [32], emphasizing the fact that mobile devices allow learning anywhere, with anyone, and with any method. There was a positive impact on academic performance in schools where mobile phones are allowed, but it depends on the way they are used, the type of activity in which they are included, and the age of maturity of students [16].

Among the pedagogical benefits and uses that teaching through mobile devices can provide, the use of these as a reinforcement tool to increase motivation and transmit content can be cited [30], being also conducive to increasing the authenticity in learning, and promoting students' autonomy [33]. Cognitively, some mobile applications have been shown to allow students to retain more knowledge than with a traditional class [34], demonstrating the potential of these tools.

\section{Conclusions}

iNaturalist is a valuable tool to carry out collaborative projects dealing with biodiversity in secondary education. The integration of citizen-science projects in secondary schools can contribute to student's engagement by combining new collaborative technologies Web 2.0 with traditional fieldwork activities to study species biodiversity. In addition, the merging of data of citizen scientists and professional scientists help to attract student attention to scientific research. It would be advisable to include this type of tools in the curricula of teacher's degrees to facilitate the involvement of secondary school teachers in citizen-science projects as a way to integrate the digital competency of learning in educational programs. 
The valuable scientific information obtained through citizen-science initiatives is often used to carry out environmental protection policies, highlighting the critical role that citizen-science plays in conserving biodiversity [35,36]. Citizens' participation in citizenscience initiatives is an effective way of acquiring content, skills, and values related to science and biodiversity. The most effective way to learn and value science is to participate in scientific research [37]. Citizen science disseminates values of respect for biodiversity and puts students in direct contact with their natural environment, allowing them to acquire more excellent knowledge about local biodiversity [38,39]. Thus, these activities can help them adopt an attitude and a sense of responsibility concerning biodiversity contributing to sustainable development and global change mitigation.

Author Contributions: Conceptualization, E.M.G. and J.P.; methodology, A.E., J.M., E.M.G., and J.P.; formal analysis, A.E. and J.M.; investigation, E.M.G. and J.P.; resources, J.P.; data curation, A.E. and J.M.; writing—original draft preparation, A.E. and I.A.; writing—review and editing, E.M.G. and J.P.; supervision, E.M.G. and J.P.; project administration, E.M.G. and J.P.; funding acquisition, E.M.G. and J.P. All authors have read and agreed to the published version of the manuscript.

Funding: This research was funded by the Education Department of the Navarra Government, grant number CENEDUCA3/2019.

Institutional Review Board Statement: Not applicable.

Informed Consent Statement: Not applicable.

Data Availability Statement: Not applicable.

Acknowledgments: We would like to acknowledge the teachers, Maite Salvatierra and Arancha García, and their secondary school students from Colegio Nuestra Señora del Puy, Estella (Navarra), for supporting the Basaula Project. This study was carried out in the context of the Master's Degree in Secondary Education Teaching of the Faculty of Human, Social and Educational Sciences at the Public University of Navarra.

Conflicts of Interest: The authors declare no conflict of interest.

\section{References}

1. Bermudez, G.M.A.; Lindemann-matthies, P. “What Matters Is Species Richness"—High School Students' Understanding of the Components of Biodiversity. Res. Sci. Educ. 2020, 50, 2159-2187. [CrossRef]

2. What is Biodiversity? Available online: https://www.amnh.org/research/center-for-biodiversity-conservation/about-the-cbc/ what-is-biodiversity (accessed on 14 February 2020).

3. Mishler, B.D. Species are not uniquely real biological entities. In Contemporary Debates in Philosophy of Biology; Ayala, J., Robert, A., Eds.; Blackwell Publishing Ltd.: Hoboken, NJ, USA, 2010; pp. 110-122. ISBN 978-1-405-15998-2.

4. Bagnoli, P.; Goeschl, T.; Kovács, E. People and Biodiversity Policies: Impacts, Issues and Strategies for Policy Action; Organisation for Economic Cooperation and Development (OECD): Paris, France, 2008; ISBN 9789264034341.

5. Ministerio de Educación, Ciencia y Deporte, Real Decreto 1105/2014. Boletín Oficial del Estado 2015, 169-546. Available online: https:/ / www.boe.es/boe/dias/2015/01/03/pdfs/BOE-A-2015-37.pdf (accessed on 14 February 2020).

6. Trumbull, D.J.; Bonney, R.; Bascom, D.; Cabral, A. Thinking scientifically during participation in a citizen-science project. Sci. Educ. 2000, 84, 265-275. [CrossRef]

7. Dickinson, J.L.; Shirk, J.; Bonter, D.; Bonney, R.; Crain, R.L.; Martin, J.; Phillips, T.; Purcell, K. The current state of citizen science as a tool for ecological research and public engagement. Front. Ecol. Environ. 2012, 10, 291-297. [CrossRef]

8. Unger, S.; Rollins, M.; Tietz, A.; Dumais, H. iNaturalist as an engaging tool for identifying organisms in outdoor activities. J. Biol. Educ. 2020, 1-11. [CrossRef]

9. Hardy, C.R.; Hardy, N.W. Adapting traditional field activities in natural history education to an emerging paradigm in biodiversity informatics. Am. Biol. Teach. 2018, 80, 501-519. [CrossRef]

10. Editorials, N. A public service. Nature 2009, 457, 8. [CrossRef]

11. Alexander, B. Web 2.0: A New Wave of Innovation for Teaching and Learning? Educ. Rev. 2006, 41, 32-44.

12. Chandler, M.; See, L.; Copas, K.; Bonde, A.M.Z.; Claramunt López, B.; Danielsen, F.; Legind, J.K.; Masinde, S.; Miller-Rushing, A.J.; Newman, G.; et al. Contribution of citizen science towards international biodiversity monitoring. Biol. Conserv. 2017, 213, 280-294. [CrossRef]

13. iNaturalist. Teacher's Guide. Available online: https://www.inaturalist.org/pages/teacher $\backslash$ T1 $\backslash$ textquoterights+guide (accessed on 16 October 2020).

14. GBIF-Global Biodiversity Information Facility. Available online: https://www.gbif.org/es/ (accessed on 14 December 2020). 
15. Sulc, M.; Picek, L.; Matas, J.; Jeppesen, T.S.; Heilmann-Clausen, J. Fungi recognition: A practical use case. In Proceedings of the 2020 IEEE Winter Conference on Applications of Computer Vision, WACV 2020, Snowmass Village, CO, USA, 1-5 March 2020; Institute of Electrical and Electronics Engineers Inc.: Piscataway Township, NJ, USA, 2020; pp. 2305-2313.

16. Gómez-García, M.; Soto-Varela, R.; Morón-Marchena, J.A.; del Pino-Espejo, M.J. Using mobile devices for educational purposes in compulsory secondary education to improve student's learning achievements. Sustainability 2020, 12, 3724. [CrossRef]

17. Braschler, B.; Mahood, K.; Karenyi, N.; Gaston, K.J.; Chown, S.L. Realizing a synergy between research and education: How participation in ant monitoring helps raise biodiversity awareness in a resource-poor country. J. Insect Conserv. 2010, 14, 19-30. [CrossRef]

18. Silva, H.; Pinho, R.; Lopes, L.; Nogueira, A.J.A.; Silveira, P. Illustrated plant identification keys: An interactive tool to learn botany. Comput. Educ. 2011, 56, 969-973. [CrossRef]

19. Michael, J. Where's the evidence that active learning works? Adv. Physiol. Educ. Educ. 2006, 30, 159-167. [CrossRef] [PubMed]

20. Shirk, J.J.L.; Ballard, H.H.L.; Wilderman, C.C.; Phillips, T.; Wiggins, A.; Jordan, R.; McCallie, E.; Minarchek, M.; Lewenstein, B.V.; Krasny, M.E.; et al. Public participation in scientific research: A framework for intentional design. Ecol. Soc. 2012, 17, 29. [CrossRef]

21. Benware, C.A.; Deci, E.L. Quality of learning with an active versus passive motivational set. Am. Educ. Res. J. 1984, 21, 755-765. [CrossRef]

22. Basaula Project.iNaturalist. Available online: https://www.inaturalist.org/projects/basaula-project (accessed on 16 October 2020).

23. Willms, J.D. Student Engagement at School. A Sense of Belonging and Participation: Results from PISA 2000; PISA; OECD: Paris, France, 2003; ISBN 9789264018921.

24. Heberling, J.M.; Isaac, B.L. iNaturalist as a tool to expand the research value of museum specimens. Appl. Plant Sci. 2018, 6, e1193. [CrossRef]

25. Huang, Y.M.; Lin, Y.T.; Cheng, S.C. Effectiveness of a Mobile Plant Learning System in a science curriculum in Taiwanese elementary education. Comput. Educ. 2010, 54, 47-58. [CrossRef]

26. Groom, Q.; Weatherdon, L.; Geijzendorffer, I.R. Is citizen science an open science in the case of biodiversity observations? J. Appl. Ecol. 2017, 54, 612-617. [CrossRef]

27. Hadad, S.; Meishar-Tal, H.; Blau, I. The parents' tale: Why parents resist the educational use of smartphones at schools? Comput. Educ. 2020, 157, 103984. [CrossRef]

28. Palmberg, I.; Kärkkäinen, S.; Jeronen, E.; Yli-Panula, E.; Persson, C. Nordic student teachers' views on the most efficient teaching and learning methods for species and species identification. Sustainability 2019, 11, 5231. [CrossRef]

29. Hodges, K.E. Enhancing student engagement and learning via the optional Biodiversity Challenge. Glob. Ecol. Conserv. 2016, 5 , 100-107. [CrossRef]

30. Sung, Y.T.; Chang, K.E.; Liu, T.C. The effects of integrating mobile devices with teaching and learning on students' learning performance: A meta-analysis and research synthesis. Comput. Educ. 2016, 94, 252-275. [CrossRef]

31. Soloway, E.; Norris, C.; Hossain, A. Using smartphones as essential tools for learning. Educ. Technol. $2011,51,18-25$.

32. Woodcock, B.; Middleton, A.; Nortcliffe, A. Considering the Smartphone Learner: Developing innovation to investigate the opportunities for students and their interest. Stud. Engag. Exp. J. 2012, 1, 1-15. [CrossRef]

33. Van Praag, B.; Sanchez, H.S. Mobile technology in second language classrooms: Insights into its uses, pedagogical implications, and teacher beliefs. ReCALL 2014, 27, 288-303. [CrossRef]

34. Furió, D.; Juan, M.C.; Seguí, I.; Vivó, R. Mobile learning vs. traditional classroom lessons: A comparative study. J. Comput. Assist. Learn. 2015, 31, 189-201. [CrossRef]

35. Kobori, H.; Dickinson, J.L.; Washitani, I.; Sakurai, R.; Amano, T.; Komatsu, N.; Kitamura, W.; Takagawa, S.; Koyama, K.; Ogawara, T.; et al. Citizen science: A new approach to advance ecology, education, and conservation. Ecol. Res. 2016, 31, 1-19. [CrossRef]

36. Greenwood, J.J.D. Citizens, science, and environmental policy: A British perspective. In Citizen Science. Public Participation in Environmental Research; Dickinson, J.L., Bonney, Y.R., Eds.; Cornell University Press: Ithaca, NY, USA, 2012 ; pp. 150-164.

37. Silvertown, J. A new dawn for citizen science. Trends Ecol. Evol. 2009, 24, 467-471. [CrossRef]

38. Trautmann, N.M. Citizen Science: 15 Lessons that Bring Biology to Life; NSTA Press: Arlington, VA, USA, 2013.

39. Wals, A.E.J.; Brody, M.; Dillon, J.; Stevenson, R.B. Science education. Convergence between science and Environmental Education. Science 2014, 344, 583-584. [CrossRef] 